\title{
Fundamentos teÓRICO-METOdOlÓGICOS DO Plano de Desenvolvimento da Escola (PDE)*
}

Sônia Maria Borges de Oliveira**

\section{RESUMO}

O PDE é um produto do programa Fundescola destinado a aperfeiçoar a gestão da escola pública, visando melhorar a qualidade do ensino oferecido. Com a implementação desse produto, o programa tem por objetivo que a escola "incorpore" a metodologia do planejamento estratégico e os princípios da qualidade total. Este artigo apresenta a análise do referencial teórico que sustenta o PDE a partir do estudo de sua metodologia e respectivos processos de elaboração e implementação por uma escola pública do município de DouradosMS, no período de 1999 a 2002. O estudo contribuiu para dar visibilidade sobre como é introduzida a ideologia implícita nas políticas educacionais contemporâneas no cotidiano de uma escola pública.

Palavras-chave: Política educacional; gestão escolar; escola pública; ensino fundamental.

\section{INTRODUÇÃO}

Este artigo apresenta parte da dissertação ${ }^{1}$ de mestrado em educação, defendida na Universidade Federal de Mato Grosso do Sul, que teve como propósito analisar o referencial teórico que sustenta o PDE a partir de sua metodologia e de seus respectivos processos de elaboração e implementação por uma escola pública, a fim de apreender em que medida esse referencial influencia na organização escolar e na participação dos sujeitos.

\footnotetext{
* Artigo recebido em 11/2/2006 e aprovado em 15/5/2006.

** Doutoranda em Educação pela Universidade Federal de Mato Grosso do Sul. [soniasete@ ibest.com.br]
} 
Para efetivação do objetivo da pesquisa, foi eleito o município de Dourados por ser a cidade pólo da segunda microrregião mais populosa do Estado de Mato Grosso do $\mathrm{Sul}^{2}$ constituindo, nos termos do programa, a zona de atendimento prioritário 2 (ZAP 2). Para coletar os dados documentais que subsidiaram a análise em torno das questões levantadas no trabalho, selecionou-se uma escola da rede municipal, ${ }^{3} \mathrm{em}$ virtude de ela ter estado no programa desde a sua implantação e atender ao ensino fundamental completo, ou seja, de $1^{\mathrm{a}}$ a $8^{\mathrm{a}}$ séries.

A análise se deu a partir da busca da relação entre as diretrizes gerais do Fundescola e/ou orientações metodológicas do PDE com os documentos produzidos no âmbito da escola. ${ }^{4}$ Embasou-se também na revisão crítica de autores que tratam das questões pertinentes ao processo de reestruturação capitalista e da reforma do Estado, da participação do Banco Mundial na definição das políticas educacionais e da presença e das influências das teorias administrativas na educação.

Para este artigo, destacou-se a análise dos fundamentos teóricometodológicos do PDE e seu respectivo processamento no cotidiano escolar, a fim de ressaltar que a implantação de uma política educacional não vem desprovida de um referencial teórico e metodológico que lhe dê o aporte necessário, para que se estabeleça como "primordial" para a resolução dos problemas.

O Programa Fundo de Fortalecimento da Escola (Fundescola), que pode ser considerado um exemplo disto, foi lançado oficialmente pelo MEC e Banco Mundial em 1998. É um programa que declara compartilhar do consenso (com nações em desenvolvimento, agências financiadoras internacionais, políticos e empresários de diversos países) de que a educação básica é um meio para distribuir renda, fomentar a produtividade e viabilizar o crescimento econômico.

Portanto, fundamentado nos princípios da gestão contemporânea, elabora diversos e abrangentes produtos que são "oferecidos" aos sistemas educacionais, acompanhados de apoio técnico e financeiro. Nesse sentido, cabe ressaltar a afirmação de Oliveira, Fonseca e Toschi (2004, p. 21):

as instituições públicas são exortadas a trilharem novos caminhos organizacionais, na linha da "autogestão" e que as aproximem das suas congêneres do setor privado; multiplicam-se as propostas de avaliação do desempenho escolar, medido pelo rendimento dos alunos 
em testes padronizados; professores são estimulados a participar de atividades que não se limitem à sala de aula, mas que se destinem à própria organização da escola como um todo.

Esta nova visão sinaliza o estabelecimento de uma nova cultura escolar, ancorada pelo tripé composto por estratégias de descentralização, autonomia e liderança no âmbito escolar.

A expectativa, segundo objetivos do programa, é de que ocorra a incorporação desses novos processos de trabalho e que, gradativamente, estados, municípios e escolas assumam como sua, e por sua própria conta, a implementação das políticas associadas aos seus produtos. Isto significa que, ao assumi-las, essas esferas administrativas estariam legitimando e consolidando os paradigmas contemporâneos de gestão.

\section{PDE: UMA “NOVA" PERSPECTIVA DE ADMINISTRAÇÃO DAS ESCOLAS PÚBLICAS}

O PDE é um produto do Fundescola destinado a aperfeiçoar a gestão da escola pública, visando melhorar a qualidade do ensino oferecido. Para o programa, a melhoria da qualidade do ensino depende da melhoria da administração da escola, dos processos que desenvolve, da sua cultura, das relações entre equipe escolar, pais e comunidade. Assim, o objetivo da gestão é "elevar o desempenho dos alunos e da escola a partir da melhoria de sua organização e funcionamento" (BRASIL, 2002, p. 11).

Para que ocorra esse aperfeiçoamento da gestão, o programa entende que o ponto de partida é conceber a escola como uma organização que deva oferecer um ensino de qualidade aos seus clientes. Para tanto, adota a metodologia do planejamento estratégico, cuja orientação encontra-se exposta no manual intitulado Como elaborar o Plano de Desenvolvimento da Escola - Aumentando o desempenho da escola por meio do planejamento eficaz, de autoria de Antônio Carlos da Ressurreição Xavier e José Amaral Sobrinho.

Segundo Xavier e Amaral Sobrinho (1999), em decorrência de pesquisas realizadas, a qualidade do ensino vem sendo vista mais como resultado de processos desenvolvidos no interior da escola do que aqueles desenvolvidos no âmbito da macroestrutura do sistema educacional. Assim, a escola não poderia mais ser gerenciada como antes, funcionando a partir de um conjunto de normas e procedimentos definidos fora de 
seus domínios. Seguindo esse raciocínio, os autores afirmam ainda que a elaboração do PDE é um primeiro passo que sinaliza que a escola deixou de ser burocrática e meramente cumpridora de normas.

Observa-se, dessa afirmação, que os autores propõem a autonomia da escola e a necessidade de ela gerar e gerenciar seus próprios processos. No entanto, ao mesmo tempo, o manual dá conta não só de uma orientação técnica minuciosa de planejamento estratégico, mas também de uma ideologia de escola decidida no âmbito da macroestrutura.

Para a elaboração propriamente dita do PDE, a escola realiza, primeiramente, um diagnóstico por meio do levantamento de dados e informações sobre a qualidade da escola, composto por três questionários denominados: perfil e funcionamento da escola, análise dos fatores determinantes da eficácia escolar e avaliação estratégica da escola. Depois, estabelece os valores, a visão de futuro, a missão e os objetivos estratégicos, constituindo a visão estratégica e, em seguida, no plano de suporte estratégico, define as estratégias, metas e ações que irão viabilizar o alcance da visão estratégica.

\section{FundAMENTOS TEÓRICO-METODOLÓGICOS DO PDE/FunDESCOLA}

Na administração capitalista contemporânea, as teorias administrativas precisaram desvincular-se das características da teoria clássica de coerção e manipulação, a fim de se integrarem em um contexto diversificado, para obter o controle da ação coletiva, por meio de práticas de motivação, cooperação e integração.

A prática da gestão passa a preocupar-se então em administrar os conflitos, desenvolvendo mecanismos que possibilitem conhecer os seus determinantes, para que possa antecipar-se a ele e trabalhar na instalação do consenso. Instalar o consenso requer controlar a ação coletiva, o que pode ser viabilizado por intermédio das relações e da integração da organização tanto no ambiente interno como no externo.

Sendo assim, as organizações precisam adotar formas mais flexíveis de gestão que, além de meio de adaptação ao mercado competitivo, possibilitariam a superação do conflito mediante a instalação do consenso. Diante dessa necessidade de mudanças na forma de gestão, importa fazer algumas considerações no que diz respeito ao âmbito educacional. Toma-se como referência, para tanto, os estudos de Sander (1995), o qual situou as elaborações teóricas que tomam a instalação do 
consenso como ponto de partida da gestão da educação na categoria que denominou "tradição funcionalista do consenso" (administração burocrática, administração idiossincrática e administração integradora), cujas raízes estão na teoria positivista. Em contraposição a essa elaboração teórica, o autor situa as teorias de raízes marxistas denominando-as como "tradição interacionista do conflito" (administração estruturalista, administração interpretativa e administração dialógica).

Segundo Sander (1995, p. 83), a gestão da educação tem sido historicamente orientada pelas teorias clássicas e psicossociológicas de organização e administração que se ocupam "da ordem, do equilíbrio, da harmonia e da integração, numa palavra, do consenso derivado de princípios gerais preestabelecidos". Portanto, a educação tem sido influenciada por teorias com bases positivistas que têm o compromisso com a manutenção estrutural e cultural da sociedade e que não se caracterizam pela criticidade, uma vez que essas teorias preocupam-se tão somente em descrever os fenômenos organizacionais e administrativos.

Os fundamentos positivistas e funcionalistas da administração tradicional são colocados em questão pelas formulações teóricas fundamentadas em teorias críticas e libertárias, reunidas na tradição interacionista do conflito e que se caracteriza como crítica, reflexiva e dialética. Para os teóricos dessa perspectiva, a tradição funcionalista não oferece explicações suficientes e adequadas sobre os fenômenos do poder, da ideologia e das contradições que permeiam o sistema educacional contemporâneo.

Em contrapartida, as teorias ligadas à tradição interacionista apresentam uma maior articulação entre diferentes contribuições conceituais e analíticas, na tentativa de explicar os fenômenos organizacionais e administrativos, sendo que cada uma delas corresponde a uma determinada posição acerca da escola e da condição humana na sociedade. De modo geral, as teorias interacionistas do conflito "preocupam-se com a conscientização e a interpretação crítica da realidade, o alcance da emancipação humana e a transformação estrutural e cultural da escola e da sociedade" (SANDER, 1995, p. 94).

Diante dessas considerações sobre a construção do consenso, constitui-se um desafio o enfrentamento às proposições históricas para a educação que se fundamentam em teorias de cunho positivista. São teorias que enfatizam a racionalidade do comportamento organizacional e desconsideram o caráter humano dos atores envolvidos, reduzindo-os a 
"objetos manipuláveis" e que não realizam a mediação dos conflitos, subordinando tudo e todos à manutenção da ordem e do progresso do capitalismo.

Esse movimento de instalação do consenso está fortemente presente no programa Fundescola e, em decorrência, no PDE. A partir de uma leitura unilateral dos altos índices de repetência e evasão e do baixo nível de escolaridade da população, são feitas afirmações de que o sistema educacional é inoperante, dada à irracionalidade e à ineficiência no seu gerenciamento. Assim, o programa busca criar o consenso em torno da idéia de que a melhoria da educação estaria na adoção de parâmetros do mercado, com a aplicação de estratégias da empresa privada na gestão da escola pública.

Portanto, para imprimir mudanças na cultura organizacional da escola, o PDE tem como base elementos da qualidade total a serem viabilizados por meio da elaboração do planejamento estratégico. Na sua composição metodológica encontram-se elementos de diferentes teorias administrativas, destacando-se, fundamentalmente, a teoria neoclássica, a administração por objetivos, a teoria do desenvolvimento organizacional e a teoria da burocracia.

A seguir será apresentada uma breve definição dessas teorias, entremeada de comentários sobre as características do PDE/Fundescola que encerram contribuições de cada uma delas.

A teoria neoclássica é uma teoria da administração de abordagem eclética, que enfatiza as tarefas, as pessoas e a estrutura organizacional. Segundo Chiavenato (1997, p. 221), a teoria neoclássica "é exatamente a teoria clássica colocada no figurino das empresas de hoje, dentro de um ecletismo que aproveita a contribuição de todas as demais teorias administrativas", dando-lhe uma configuração mais ampla e flexível. Assim, a administração é considerada um processo operacional que envolve as funções de planejamento, organização, direção e controle.

Do planejamento, importa destacar o estabelecimento de objetivos e os níveis de planejamento. Os objetivos são pretensões futuras, cuja formulação deve ser consensual, participativa e hierarquizada conforme sua importância. Quanto aos níveis, estes podem ser estratégico, tático e operacional. O plano de ação do PDE contempla os três níveis de planejamento e acrescenta a quantificação e a mensuração por meio dos itens "resultado esperado" e "indicador". A quantificação e a mensuração 
são características retiradas da teoria administração por objetivos, que será abordada posteriormente.

A função de organização consiste em dividir o trabalho, agrupar as atividades em uma estrutura lógica, designar as pessoas para sua execução, alocar os recursos e coordenar os esforços para que os objetivos sejam alcançados. Essa função está presente na configuração global do Fundescola, quando: organiza, para cada estratégia, os produtos necessários ao alcance de seus respectivos objetivos; define uma estrutura gerencial e hierárquica desde o âmbito nacional até o interior da escola; estipula os valores e a forma de aplicação dos recursos a serem repassados para cada ação ou produto e mantém o controle mediante prescrição de normas e diretrizes operacionais, geralmente oriundas do Bird.

A direção - terceira função administrativa - orienta e indica o comportamento das pessoas na direção dos objetivos estabelecidos. Segundo Chiavenato (1997, p. 271), "para que a empresa possa realizar o que foi planejado dentro do esquema que foi organizado para atingir seus objetivos, as pessoas devem ser dirigidas". Isso é feito por meio de um processo de influenciação das pessoas, fundamentado nos conceitos de autoridade e poder. Nessa perspectiva, o administrador deve comunicar, liderar e motivar as pessoas, influenciando-as e dirigindo-as.

Dirigir é o ato de interpretar os planos para os outros e dar as instruções sobre como interpretá-los, formando uma hierarquia na qual os diretores dirigem os gerentes, os gerentes dirigem os supervisores e os supervisores dirigem os funcionários. Nesse sentido, destaca-se especialmente a estrutura gerencial estabelecida pelo programa Fundescola para o âmbito da escola. Trata-se de uma rede de controle, na qual um controla o trabalho do outro velado pela idéia de participação.

A última função administrativa - o controle - busca garantir que $o$ que foi planejado, organizado e dirigido realmente cumpra os objetivos pretendidos. $\mathrm{O}$ controle apresenta quatro fases, que são: estabelecimento de padrões; monitoramento do desempenho; comparação do desempenho com o padrão estabelecido; ação corretiva. O controle dos resultados, no âmbito do programa, ocorre principalmente por meio da sua articulação com a realização do Saeb e da manutenção de programas e sistemas de informações gerenciais e estatísticas. Para o monitoramento de desempenho, o programa realiza o ranking de escolas, de municípios, de estados e incentiva a definição de padrões de desempenho para alunos e professores. 
Enfim, todos esses procedimentos administrativos são realizados em prol do alcance da eficiência e eficácia da empresa ou instituição. A eficácia refere-se à capacidade da empresa em satisfazer uma necessidade da sociedade por meio de seus produtos, ao alcance dos objetivos visados e à medida dos seus resultados. A eficiência é uma relação entre recursos aplicados (custos) e o produto final obtido (benefício), voltada para a melhor maneira pela qual as coisas devem ser feitas ou executadas, a fim de que os recursos sejam otimizados. A eficiência preocupa-se com os meios e a eficácia com os resultados.

Assim, o Fundescola, para ser eficaz, define suas ações como produtos que, se empregados corretamente, irão satisfazer as necessidades dos pais e alunos - clientes da escola - no que tange a melhoria da qualidade do ensino. Para ser eficiente, racionaliza a gestão e a aplicação dos recursos como ação de controle dos meios, para buscar a excelência nos resultados.

A administração por objetivos (APO) surgiu nos anos 1950 quando os empresários americanos, que vinham sofrendo com a crise de 1929, exerciam uma administração por pressão. Sob a pressão econômica desse período, os empresários exigiam melhores resultados dos gerentes (que se mantinham apáticos) e endureciam o sistema de controle sobre eles, por julgarem a apatia como uma forma de resistência. Este círculo vicioso - maior resistência, maior controle - precisava ser rompido. Também, a teoria neoclássica vinha deslocando a sua ênfase nas "atividades-meio" para os resultados, ou seja, para os objetivos da organização.

Nessa perspectiva, a APO introduz as idéias de descentralização das decisões e de administração por resultados, as quais se efetivam mediante o emprego de uma técnica sistemática de gerência que dá forte ênfase no planejamento e no controle. Assim, a administração por objetivos tem como principais características o estabelecimento conjunto e interligado de objetivos, a ênfase na mensuração e no controle de resultados, a avaliação e revisão contínua dos planos e a participação atuante das gerências.

A APO orienta-se basicamente no planejamento estratégico e nos planos táticos da teoria neoclássica. O planejamento estratégico, que define o PDE, refere-se

à maneira pela qual uma empresa pretende aplicar uma determinada estratégia para alcançar os objetivos propostos" e possui quatro 
fases bem definidas, que são "formulação dos objetivos organizacionais, análise interna da empresa, análise externa do ambiente e formulação de estratégias. (CHIAVEnATO, 1997, p. 375)

Na formulação dos objetivos organizacionais, são definidos os objetivos de longo prazo, sua ordem de importância e prioridade. Observase que a metodologia do planejamento estratégico foi levada para o âmbito das secretarias a partir da elaboração do planejamento estratégico da secretaria (PES) e, para a escola, por meio do PDE. Ocorre que, embasado nesse tipo de planejamento, o objetivo a ser alcançado a longo prazo e as respectivas estratégias já estavam estabelecidos pela cúpula organizacional, ou seja, pelo programa. Assim, a efetivação dos objetivos é transferida para os "meros" executores dessas políticas no âmbito escolar, por meio da elaboração de um plano estratégico e "participativo". Ocorre que os sujeitos da escola também têm expectativas e objetivos para a sua área de trabalho que podem contradizer com o objetivo proposto nas instâncias superiores. Por isso, a implantação de uma política educacional não vem desprovida de um referencial teórico metodológico que lhe dê o aporte necessário, para que se estabeleça como primordial para a resolução dos problemas.

A análise interna das forças e as limitações da empresa consistem na avaliação dos pontos fortes (forças propulsoras que facilitam o alcance dos objetivos organizacionais) e dos pontos fracos (limitações e forças restritivas que dificultam ou impedem o alcance dos objetivos). Requer analisar os recursos disponíveis (pessoas, financeiro, equipamentos etc.), a estrutura organizacional e a avaliação do desempenho.

A análise externa do meio ambiente permite conhecer as condições externas que impõem desafios (ou ameaças) e oportunidades à empresa. É preciso identificar as tendências e a atratividade do ambiente de atuação da empresa e conhecer as características de seus competidores.

As análises interna e externa, no planejamento estratégico, visam dar respostas consistentes às forças e fraquezas internas e às oportunidades e ameaças externas, a fim de que a empresa alcance e mantenha um desempenho competitivo. A formulação das alternativas estratégicas é o momento em que a empresa elabora os meios para alcançar os objetivos organizacionais, tendo em vista as condições interna e externa.

Estas características estão presentes, principalmente, na terceira etapa da elaboração do PDE, quando a escola deve definir seus valores, 
visão de futuro e missão para, depois, estabelecer os objetivos estratégicos, as estratégias, as metas e, por fim, elaborar o plano de ação. A análise das condições interna e externa da instituição ocorre principalmente no questionário 3, quando avalia suas forças e fraquezas (internas) e as ameaças e oportunidades (externas) a fim de, ao identificar essas variáveis, poder planejar segundo suas potencialidades internas e as oportunidades externas.

As quatro fases do planejamento estratégico estão consolidadas na metodologia do PDE, sendo distribuídas, principalmente, nas etapas do diagnóstico, da visão estratégica e do plano de suporte estratégico.

Segundo Chiavenato (1997), a APO, depois do apogeu, caiu em descrédito por cometer três exageros que estão relacionados ao excesso de regulamentos e papelório, à autocracia e à motivação negativa causada pela imposição de objetivos exagerados aos subordinados. Entretanto, ressalta o autor, a APO ressurgiu recentemente com uma roupagem mais moderna, amigável, democrática e participativa, uma vez que, de modo geral, procura envolver gerentes e subordinados nas discussões e decisões em torno dos objetivos da empresa. Acredita-se que o PDE, como planejamento estratégico, tem uma identificação com essa nova roupagem da $\mathrm{APO}$, tendo em vista o discurso em torno da promoção de práticas mais democráticas e participativas no interior da escola.

A teoria do desenvolvimento organizacional é uma construção teórica que surge do movimento de diversos autores, no sentido de aplicar as ciências do comportamento na administração. Portanto, é uma teoria de abordagem comportamental, também chamada behaviorista.

O conceito de desenvolvimento organizacional está ligado aos conceitos de mudança e de capacidade adaptativa da organização à mudança. Toda organização se relaciona com o meio ambiente e depende desse relacionamento para sobreviver. Assim, para mudar uma organização não basta mudar sua estrutura. É necessário mudar sua cultura entendida como modo de vida próprio da organização que repousa sobre valores, crenças, tradições e hábitos - e influenciar o clima organizacional que está ligado "ao moral" e à satisfação das necessidades humanas dos participantes.

O processo de mudança organizacional depende da capacidade inovadora da organização e de estar aberta para absorver uma nova idéia ou um novo comportamento, com vistas ao desenvolvimento. Em relação a essa motivação para aceitar o "novo", já no momento da 
capacitação do PDE, o programa prepara os participantes exibindo filmes de curta duração, que falam da necessidade de mudar os paradigmas, de ter visão de futuro, de adaptar-se aos novos ambientes e de trabalhar em equipe.

Nesse sentido, o PDE como um todo conjuga esforços para promover mudanças na organização escolar, ao realizar ações, como ênfase na liderança do diretor, o qual deve agregar todos em torno dos objetivos propostos; desconcentração de tarefas, para que todos assumam responsabilidades e sejam responsáveis por seus resultados; criação de novas relações de trabalho entre funcionários e professores, ao definir uma estrutura gerencial; formalização de registros e incentivo à avaliação constante, permitindo a imediata correção de ações sem resultados satisfatórios.

A burocracia surgiu, nos anos 1940, da necessidade de se ter uma teoria da organização sólida e abrangente para orientar o trabalho do administrador, que superasse o mecanicismo da teoria clássica e o romantismo ingênuo da teoria das relações humanas. A burocracia é uma forma de organização humana que se preocupa com a adequação dos meios aos objetivos pretendidos, a fim de garantir a máxima eficiência no alcance desses objetivos. Sua base, portanto, está na racionalidade.

Para a adequação dos meios aos fins, ou seja, para ser eficiente, a burocracia define detalhadamente como as coisas deverão ser feitas. Assim, suas características são: presença de normas e regulamentos; formalidade nas comunicações; racionalidade e divisão sistemática do trabalho; impessoalidade nas relações; hierarquia de autoridade; rotinas e procedimentos padronizados; ênfase na competência técnica e na meritocracia; separação do corpo administrativo dos proprietários; profissionalização dos ocupantes dos cargos; e completa previsibilidade do funcionamento via previsão do comportamento dos funcionários.

A burocracia está presente na fundamentação do programa Fundescola principalmente pelo seu conceito de racionalidade - adequação dos meios aos fins -, conferindo-lhe autoridade para propor os produtos - meios - considerados necessários e adequados para o alcance dos objetivos - fins - para a educação.

A qualidade total caracteriza-se como uma forma de gerenciamento que promove a adesão de todos aos objetivos da empresa, por intermédio da abertura de espaços à intervenção dos trabalhadores. 
Contudo, tal intervenção limita-se, em geral, "a questões de ordem técnica, muito mais que financeiras ou administrativas" (OliveIRA, 1996, p. 75).

Segundo Oliveira (1998), a participação exigida do trabalhador restringe-se ao gerenciamento da rotina, portanto, permanecem as formas hierárquicas de poder e a separação entre concepção e execução. E ainda, para garantir a total participação de todos, lança mão de mecanismos de cooptação e controle que se realizam por meio da comprovação por fatos e dados, da mensuração e quantificação, da ênfase nos resultados e, principalmente, da definição de normas e padrões.

Portanto, o controle da qualidade total caracteriza-se pelo gerenciamento como forma de estabelecer, manter e melhorar os padrões e manter o disciplinamento dos trabalhadores. Segundo Oliveira (1998, p. 65), o "gerenciamento por diretrizes" objetiva alcançar esses padrões, dividindose em:

a) Gerenciamento pela Organização ou de Rotina, que faz o controle do trabalho diário pelo emprego de tarefas repetitivas, suscetíveis de previsão, que são executadas pelos trabalhadores de base, os quais também desempenham funções de manutenção. Embora este gerenciamento faça uma articulação entre planejamento e execução, não rompe com a fragmentação de tarefas, uma vez que restringe aos pequenos elos da cadeia.

b) Gerenciamento Interfuncional: busca criar o perfil, a visão da organização, engendrando suas metas estratégicas e visando a melhoria dos processos e o nível de competitividade. Este gerenciamento é realizado pela alta administração.

Estas duas formas de gerenciamento demonstram que as decisões e os rumos da empresa ficam nas mãos de uma cúpula, cabendo aos trabalhadores apenas conhecer e executar bem suas tarefas para manter o seu bom funcionamento. Permanece, portanto, a fragmentação do trabalho, embora o trabalhador tenha sido solicitado a participar e a se envolver mais com as questões de sua empresa.

Ressalta-se que o gerenciamento, realizado pelo PDE/Fundescola, apresenta tanto as características do gerenciamento de rotina quanto do interfuncional. A realização do gerenciamento da rotina pode ser verificada, no PDE, por intermédio do questionário 2 que, ao fazer um rol de características relacionadas a uma escala de pontuação que no seu ponto máximo define a eficácia da escola, está francamente ditando e padronizando como devem agir os sujeitos que fazem a escola. 
Quanto ao gerenciamento interfuncional, este está presente no Fundescola, uma vez que a definição de qual qualidade seria pretendida para a educação se deu na cúpula formada pelos técnicos do programa, respaldados pelas diretrizes dos organismos internacionais. A direção que a educação deveria tomar diante dos requerimentos do mundo produtivo foi definida pela alta administração, cabendo aos trabalhadores que estão na escola executar as ordens, fazendo, no máximo, pequenos arranjos ou ajustes. As ordens, por sua vez, são escamoteadas por meio de modelos gerenciais mais flexíveis e participativos e recobertas pelo discurso da qualidade.

A qualidade é um termo que se reveste de muitos significados. ${ }^{5}$ No caso do controle da qualidade total, ela é definida como uma técnica empresarial provocada por uma gestão estratégica do trabalho que objetiva satisfazer o consumidor. É oferecer um produto de acordo com as especificações, formato e desenho requeridos pelo cliente. Também significa fazer o certo - para evitar desperdício e retrabalho - e ter preço competitivo.

Por isto, a qualidade deve estar ligada à missão da empresa, identificando-se com ela, e exige a participação de todos para promover uma visão compartilhada. Também os sistemas de controle são importantes mecanismos de promoção da adesão de todos à missão da empresa. Verifica-se que o PDE realiza o círculo de controle da qualidade por meio do emprego do Ciclo PDCA (denominado como triângulo estratégico da escola) e da formação das equipes do plano de ação que, entre outras atribuições, devem realizar reuniões constantes para acompanhar e avaliar o andamento das ações, sendo permitido agirem corretivamente sobre aquelas que não estão apresentando resultados satisfatórios.

\section{O PDE NA ESCOLA}

Em relação à implementação do PDE na escola, analisou-se como foram encaminhados e desenvolvidos os processos de elaboração e implementação do plano, buscando compreender em que medida esses processos atendem às expectativas do programa e/ou são redimensionados pelas características políticas, culturais e sociais presentes no cotidiano da escola.

No que se refere à etapa de elaboração do PDE, os registros, de modo geral, demonstram o cuidado em atender às orientações do manual 
e das recomendações oriundas tanto do momento da capacitação quanto dos técnicos do programa. Entretanto, observa-se que houve uma preocupação maior nesse atendimento no primeiro ano de elaboração do PDE, inclusive, sendo possível verificar que os próprios registros são mais minuciosos, embora com um caráter mais técnico do que analítico e esclarecedor.

Nas demais elaborações correspondentes aos anos de 2000 e 2001, percebe-se que há um melhor domínio da metodologia do PDE por parte dos "elaboradores"; contudo, é possível verificar um movimento de reajuste ou reorientação em torno dela, gerando alguns conflitos. Para os agentes da escola, essas reorientações apresentam aspectos contraditórios, pois podem tanto trazer facilidades para elaboração do plano quanto constituir uma sensação de "incompetência" para tal. Para os técnicos do programa, geralmente, essa situação decorre da inexperiência histórica desses agentes em relação ao planejamento, reforçada pela não "incorporação" da metodologia.

Corrobora, nesse sentido, Marra, Bof e Amaral Sobrinho (1999), os quais, ao avaliarem o processo do PDE nas escolas, apresentam como seus obstáculos, entre outros, a dificuldade da equipe escolar em trabalhar com atividades de planejamento e o não entendimento da metodologia. Face a essa avaliação, pode-se afirmar que os autores escamoteiam o fato de que um planejamento pautado nos princípios da qualidade total não se constitui em prática comum no âmbito escolar.

Dada essa dificuldade, verifica-se que a escola se "apegou" aos exemplos contidos no manual, principalmente no momento da elaboração das ações. Assim, considera-se que a exposição de tais exemplos cumpre papel fundamental na conformação da escola aos propósitos da racionalidade, eficiência e eficácia do programa. Nessa perspectiva, ações que apresentam a definição de padrões de desempenho, premiações de alunos e funcionários, definição de critérios de eficácia escolar, envolvimento dos pais, treinamento em serviço e mensuração de desempenho escolar foram encontradas nos registros da escola.

A realização das ações dessa natureza, bem como daquelas baseadas em práticas já vivenciadas na escola, deu-se por meio da implementação do plano de ação; no entanto, a sua efetivação, ou não, é informada pelos relatórios de acompanhamento do plano de ação que apresentam a aplicação dos indicadores de cada ação e das metas. 
Para o PDE, o uso da mensuração é uma forma de a escola aumentar sua eficiência, aumentando, assim, a satisfação dos clientes em relação aos serviços prestados. A aplicação dos indicadores, para medir a ação ou a meta, constitui um ápice da racionalidade técnicoburocrática na busca da eficiência, imposta para a escola.

Segundo Etzioni (1984), a mensuração da eficiência apresenta problemas delicados, principalmente quando esta é proposta para organizações cujo rendimento não é material, pois a mensuração exige a definição de um padrão. Eis aí, portanto, um fator que justifica a dificuldade dos atores escolares em elaborar ações nos moldes exigidos pela metodologia do PDE, ou seja, quantificar suas práticas.

Diante do exposto, avalia-se que, por um lado, o uso da mensuração no PDE como garantia de execução das ações e, conseqüentemente, a efetivação de seus objetivos mais amplos não deram conta de garantir os objetivos esperados. Isso só demonstra que não é possível a quantificação do conteúdo e das práticas inerentes ao espaço escolar, pois sua produção não resulta em bens materiais e nem é passível de mensuração. Por outro lado, toda essa orientação metodológica logra o mérito de reforçar práticas classificatórias, adaptativas, discriminadoras, seletivas e meritocráticas ainda vigentes no cotidiano escolar.

Os relatórios preenchidos pela escola dão conta de que a maioria das ações foi cem por cento (100\%) realizada, sendo que algumas alcançaram parcialmente os resultados esperados e poucas não foram realizadas. Entre as que se realizaram 100\%, estão aquelas relacionadas às práticas mais cotidianas e às de aquisições. As ações elaboradas com base nos exemplos ou no discurso dos técnicos do programa estão entre as parcialmente realizadas, ou se são totalmente realizadas, geralmente, não são mantidas nem nos planos posteriores, nem são incorporadas na prática cotidiana. Apenas a premiação de funcionários, que foi introduzida na escola pelo PDE, foi realizada mais de uma vez e ganhou visibilidade na comunidade escolar por meio de boletim informativo.

As aquisições viabilizadas pelo repasse do recurso vinculado ao plano constituem um outro aspecto do PDE que merece destaque em relação à sua implementação na escola. Primeiramente, cabe tecer algumas considerações acerca da relação do repasse de recursos para a escola com o discurso da autonomia, e, em segundo lugar, analisar os benefícios desses recursos para a prática educativa. 
Para o Fundescola, o repasse de recurso direto para escola é um passo no processo de autonomia das escolas e estímulo à participação dos pais na administração dos recursos. No entanto, os recursos que chegam diretamente em uma conta bancária específica para a escola são os referentes ao programa de adequação dos prédios escolares (PAPE) - com destino específico para reforma das salas de aula e definição de como deve ser essa reforma; ao projeto de melhoria da escola (PME) decorrente da elaboração PDE, cuja ingerência metodológica deixa poucas decisões a serem tomadas; ao programa dinheiro direto na escola (PDDE) - destinado à cobertura de despesas de custeio, manutenção e pequenos investimentos em equipamentos. Estes dois últimos programas delimitam que o uso do recurso seja de $40 \%$ em materiais permanentes e $60 \%$ em materiais de consumo, não sendo permitido gastos com pessoal.

Assim, é obvio o questionamento acerca de que "decisões" sobram para os pais ou mesmo para a equipe escolar tomarem. Verifica-se que é um campo estrito e limitado que possibilita apenas decidir se é melhor para o processo ensino e aprendizagem adquirir um televisor ou um retroprojetor, comprar tesouras ou tintas, consertar o muro ou o encanamento, conforme o valor disponível e as regras para utilização.

Esse quadro demonstra que o Fundescola inviabiliza a inevitável e necessária relação entre autonomia e participação, uma vez que, para que os sujeitos exerçam a autonomia, o principal requisito é sua participação não em decisões menos importantes ou predefinidas, mas na concepção, definição e construção das políticas que se deseja realizar.

Quanto aos benefícios que os recursos visam proporcionar, segundo manual do PME (BRAsIL, 1999, p. 1), para a "melhoria dos processos pedagógicos" e, conseqüentemente, "a melhoria do desempenho dos alunos", poucos registros avaliativos foram encontrados. Por intermédio dos PDEs e PMEs, pode-se verificar o que foi adquirido com os recursos; no entanto, não constam nas atas e nos relatórios maiores informações sobre o uso, resultados ou benefícios desses materiais e equipamentos adquiridos. Diante disto, avalia-se que a escola vem adquirindo muitos materiais didático-pedagógicos e bens permanentes, mas que não tem conseguido desenvolver um trabalho articulado entre os recursos didáticos disponíveis e a prática pedagógica.

O movimento de implementação do PDE na escola é acompanhado e controlado por meio de mecanismos tanto internos quanto externos. 
Os internos realizam-se mediante reuniões constantes, registros em atas e relatórios mensais; os externos, por meio de relatórios dos assessores técnicos, do ranking, das pesquisas encomendadas, de estudos técnicos.

No âmbito da escola, os documentos demonstram que o empenho nesse acompanhamento foi maior no período que corresponde à atuação mais presente dos técnicos da secretaria de educação e do Fundescola. $\mathrm{E}$, ainda, que o teor dos registros é extremamente técnico, informando, na maioria deles, apenas a realização das etapas de trabalho e se as ações foram realizadas ou não. Portanto, avalia-se que eles vêm sendo realizados mais para atender formalidades metodológicas do que como uma necessidade detectada pela equipe escolar como forma de documentar, analiticamente, suas práticas e decisões, ou seja, registrar a história da trajetória escolar.

Dessa análise sobre a implementação do PDE, pode-se observar que a escola atendeu, quase na totalidade, às orientações metodológicas do manual. No entanto, os documentos não demonstraram que esse zelo metodológico tenha revertido significativamente os principais problemas levantados na análise situacional, como os altos índices de repetência, o pouco envolvimento dos pais e a organização da rotina escolar. Diante disto e reportando-se às expectativas do programa em relação à "incorporação" do PDE por parte da escola, fica a indagação: será que a escola incorporou a metodologia do PDE, ou tomou-o apenas como mais uma tarefa a ser cumprida de forma que não fez a diferença esperada?

Quanto à participação dos sujeitos e da comunidade, buscouse analisar de que forma estes são solicitados a participarem e como participam, tendo como pressuposto que o caráter de tal participação está estreitamente ligado tanto à retórica neoliberal quanto aos requisitos da administração contemporânea.

No conjunto, os registros escolares demonstram que os sujeitos que compõem a equipe escolar - foram "solicitados" a participar do projeto que ora chegava à escola. Esta afirmação fundamenta-se no fato de que um dos princípios que regem a implantação do PDE, segundo Amaral Sobrinho (2001), é o trabalho em equipe. Este princípio, advindo de teorias administrativas ligadas tanto à escola da administração científica quanto às relações humanas, tem sido ressignificado, principalmente, no modelo da qualidade total.

Diante das novas necessidades técnicas de produção, o trabalho em equipe passa a ter a finalidade de promover a participação e o 
envolvimento do trabalhador com a empresa, em uma perspectiva gerencialista. Portanto, a participação, escamoteada por um discurso falacioso de que esta se dá em nível das decisões, busca tão-somente lograr o envolvimento do trabalhador no ponto exato para executar com comprometimento as tarefas da produção rumo aos objetivos, enfatizase, da organização. Segundo Motta (1998, p. 56), as abordagens estruturalistas sobre as organizações fazem a crítica a esse caráter ilusório, uma vez que a tão celebrada participação nas decisões é

uma forma de fazer com que os subordinados acatem decisões previamente tomadas, em função de uma ilusão de participação e de poder, geralmente criada pela delegação de autoridade para decidir em assuntos absolutamente indiferentes para a alta cúpula administrativa.

Nessa perspectiva, o PDE, ao mesmo tempo em que incita os sujeitos a participarem mediante discurso da autonomia, do trabalho em equipe, da responsabilização e da cooperação, induz essa participação ao estabelecer uma estrutura gerencial para o interior da escola com funções definidas. As pessoas se "encaixam" segundo a função que desempenham, ou são "encaixadas" por designação, como é o caso da definição de um coordenador pedagógico para ser o coordenador do PDE.

Os registros da escola demonstram que todos os elementos da estrutura gerencial foram preenchidos. O comitê estratégico que é, segundo o manual, a instância máxima para o acompanhamento e o controle do PDE, foi oficialmente composto, mas não há registros de que demonstrem que tenha atuado regularmente. A avaliação possível por meio das atas é a de que tal função foi praticamente desempenhada pelo coordenador do PDE. Essa constatação contraria a ênfase e expectativa que o programa coloca sobre a figura do diretor, no sentido de ele ser o elemento catalisador da mobilização da comunidade interna e externa, em prol do sucesso do PDE na escola.

Os papéis como líderes de objetivos, gerentes de metas e responsáveis por ações dão mostras de como se constituem os grupos de trabalhos com base gerencial, no qual um exerce o controle sobre o trabalho do outro, em uma ilusão de que todos estão envolvidos e participando ativamente da gestão escolar. No entanto, em relação aos profissionais que desempenham esses papéis na estrutura gerencial da 
escola, denota-se dos registros uma atuação técnica, isto é, apenas cumpridora das orientações do manual. Assim, seria possível afirmar que esse procedimento demonstra um aspecto do caráter pedagógico do PDE, no que se refere a adequar as pessoas a uma determinada organização de trabalho. Entretanto, a análise dos documentos da escola não possibilita afirmar que elas já internalizaram e aceitaram a metodologia como prática rotineira, ou que haja uma negação dos sujeitos ao trabalho proposto.

Em relação ao envolvimento dos pais e da comunidade com a escola, o manual aponta, para que a escola seja eficaz, que eles participem das atividades promovidas pela escola, façam sugestões para sua melhoria e para o enriquecimento do conteúdo. E ainda, ampliando o campo de participação destes, Amaral Sobrinho (s.d.) afirma que as famílias e a comunidade devem apoiar a secretaria de educação na tarefa de prover condições físicas para o bom funcionamento das escolas.

No caso da escola pesquisada, a expectativa demonstrada, por meio das características priorizadas no questionário 2 dos PDEs dos anos 1999, 2001 e 2002, refere-se apenas à participação dos pais nas reuniões de avaliação na escola e ao acompanhamento dos deveres de casa. Para resolução dos problemas relacionados à integração dos pais com a escola, estabeleceram como meta implementar atividades como: torneio de futebol de salão para os pais; gincana para as mães; realizar um dia de louvor; jogos internos; divulgação do PDE e ações da escola via faixas e jornal informativo; reuniões com pais de alunos que demonstrem dificuldades de aprendizagem. Para os problemas relacionados ao envolvimento dos pais com a aprendizagem, propôs-se fazer um questionário para diagnosticar a realidade de vida dos alunos; realizar um seminário com os pais para discutir os resultados do questionário; passar orientações para os pais que participaram do seminário; promover palestras.

Cabe ressaltar que lograr o envolvimento dos pais não é um projeto fácil de realizar-se, principalmente, se elaborado por meio de planos estratégicos, com ações pensadas e propostas em uma via de mão única. É preciso perguntar: Quais são as necessidades dos pais? O que esperam da escola? Como podem participar?

Avalia-se que os mecanismos de envolvimento e participação, incentivados pelo programa buscam o engajamento de todos em torno de objetivos definidos na macroestrutura, com vistas a estabelecer a cultura 
organizacional necessária. Esse engajamento, ao ser estendido aos pais e à comunidade, atenderia também à necessidade de responsabilizá-los pela manutenção da escola e pelos resultados dos alunos. Portanto, o limite da participação encontra-se nesse paradoxo: envolver-se para assumir compromissos com a manutenção da escola e seus resultados, mas aceitar o "produto" que lhe é destinado.

Quanto à organização escolar, buscou-se analisar em que medida a implementação do PDE introduz mudanças na escola na direção do objetivo do Fundescola de elevar o desempenho dos alunos a partir da melhoria de sua organização e de seu funcionamento.

A gestão escolar, colocada pelo programa nos termos da gestão empresarial, tem sua implementação proposta com base em processos gerenciais, o que implica incorporação de princípios competitivos, seletivos e meritocráticos. Por sua vez, isso demanda práticas de consenso, de administração de conflitos, de enfoque ao cidadão-cliente, de liderança, de uso de padrões de desempenho, de avaliação por mérito, entre outras.

Estas características são "sugeridas" à escola por meio das orientações e dos exemplos do manual, das orientações verbais dos técnicos do programa, do discurso presente em mensagens repassadas por intermédio de filmes e/ou de textos em reuniões ou capacitações. Enfim, uma série de informações que buscam criar o clima propício para introdução de mudanças no fazer escolar e disposição para enfrentá-las em nome da inovação, da modernização e do sucesso, para a tão almejada qualidade do ensino.

Em relação à gestão, a escola pesquisada declarou, nos diagnósticos dos PDEs dos anos 1999, 2001 e 2002, que a direção, o conselho escolar e a APM são atuantes, mas confirma também que os objetivos da escola não são claros e aceitos por todos e que há, ainda, problemas na condução dos processos devido ao desconhecimento desses objetivos e à ausência de avaliação dos resultados dos trabalhos. Convém ressaltar que a escola faz sua auto-análise com base nos itens contidos no manual, portanto, torna-se difícil dimensionar suas reais práticas.

Apesar dessa observação, cabe analisar aquilo que a escola registrou como sua avaliação. Assim, observa-se que há uma dissonância no que o diagnóstico aponta em relação à escola ter direção, conselho escolar e APM atuantes e não obter o envolvimento e comprometimento da equipe de forma geral. 
Avalia-se que a atuação dessa equipe diretiva não tem se constituído em uma prática democrática de forma a desencadear um trabalho verdadeiramente coletivo. Mas parece não ser esta a análise realizada pelo grupo de sistematização e equipes do plano de ação ao elaborarem as ações para combater tal problema. As ações propostas - como por exemplo: "avaliar todos os funcionários da escola", "palestra sobre relações humanas", "estudos sobre gestão participativa e os objetivos de cada função na escola", "premiar o melhor funcionário" - recaem sobre os sujeitos mais no sentido de aprimoramento de seu desempenho individual do que em ações que possibilitem desenvolver práticas coletivas.

O detalhamento dessas ações permite levantar algumas questões: será que a escola avaliou o caráter e a dimensão de tais ações? Analisou em que medida elas são pertinentes para uma escola pública? Que tipo de envolvimento e comprometimento é possível obter dos funcionários com ações dessa natureza? Essas ações são intenções reais da escola ou influenciadas pelo "clima" teórico-metodológico do Programa? E, ainda, cabe questionar em quais momentos o conselho escolar e a APM têm sido atuantes, uma vez que, no que se refere aos registros de reuniões de acompanhamento do PDE, sua presença é praticamente nula.

Afora as indagações, tais ações dão fortes indícios de uma gestão verticalizada - que seguramente não é exclusivo da escola pesquisada , representando uma prática de administração escolar arraigada no centralismo burocrático e no autoritarismo.

As ações demonstram também que a implementação do PDE na escola recrutou um certo número de pessoas em torno das funções referentes à estrutura gerencial, as quais passaram a se envolver em atividades diferentes da que desempenham cotidianamente (dando uma aparência de participação) e desencadearam ações que requereram tomadas de decisões (simulando certa autonomia) referentes à reorganização de espaços físicos, à aquisição de diversos materiais que reequiparam a escola, à organização de capacitações, entre outras.

No entanto, avalia-se que o tipo de envolvimento e o alcance das decisões assumem apenas uma nova roupagem que, na essência, resulta em realimentar velhas práticas administrativas. Portanto, pode-se afirmar que o PDE, ao mesmo tempo em que introduz novos mecanismos de gestão, realimenta, dissimuladamente, o centralismo burocrático. 


\section{CONSIDERAÇÕES FINAIS}

A análise da metodologia e dos princípios do PDE/Fundescola possibilitou elucidar que estes foram estruturados com base no paradigma gerencial contemporâneo e buscam promover uma nova cultura na organização escolar. O paradigma gerencial contemporâneo exige formas flexíveis de gestão e se fundamenta nos princípios da autonomia, da participação e da descentralização. Na ótica do programa, a promoção desses três princípios no interior da escola seria condição básica para a melhoria da qualidade do ensino, uma vez que a escola estaria gerando e gerenciando seus processos mediante um trabalho coletivo.

A qualidade do ensino é entendida, no âmbito do programa, segundo a ótica da qualidade total, na qual é visualizada em uma perspectiva mercadológica cujos parâmetros são a relação custo-benefício e a definição do indivíduo como cidadão-cliente. Esta concepção não é elucidada na definição dada no manual, mas está explicitada tanto na metodologia do PDE quanto nos procedimentos do programa em geral, essencialmente, pela ênfase nos padrões e índices de desempenhos, pelo uso excessivo da mensuração, pelo fomento à competitividade e pela preocupação com a relação custo-benefício no financiamento da escola.

Portanto, trata-se de uma concepção de qualidade que anda na contramão de um trabalho de reconstrução da educação, no sentido de ser uma atividade que realize a emancipação humana e social. Ou seja, a construção de uma educação cuja qualidade esteja voltada para a formação de sujeitos capazes de produzir outras formas de relação econômica, social, cultural e política, superadoras das formas atuais (CAMINI, 2001).

Em relação à presença do PDE na escola, a descrição e a análise dos processos de elaboração e implementação permitiram observar o cumprimento fiel das orientações metodológicas referentes a cada etapa do plano. Ressalte-se que a fidelidade à metodologia pode ser observada nos planos elaborados e também no caráter dos registros. Entretanto, a análise desses documentos não permite afirmar que a escola tenha incorporado a metodologia de maneira a satisfazer a expectativa do programa, expressa em seus objetivos e, também, as informações documentais não são suficientes para dimensionar o quanto o PDE alterou, ou vem alterando, a organização escolar. 
Também cabe considerar que o PDE, por ser "proposto" para a escola mediante um modelo de gestão que não lhe é comum e com manual a ser seguido ipsis litteris, constitui-se em um projeto alheio a ela. Os conceitos, a metodologia, os objetivos, o modelo de gestão não foram pensados ou propostos pela escola, mas, sim, foram concebidos com vistas na macroestrutura do sistema educacional. Assim, os profissionais da escola agem a serviço de objetivos e de um projeto que não puderam eleger, constituindo um quadro semelhante à organização da produção. Nesta, os trabalhadores não participam da concepção do produto e de como fazê-lo e, no caso do PDE, os profissionais da escola também foram apartados de tais decisões.

Portanto, os objetivos do PDE/Fundescola, por mais que na aparência sejam oportunos e necessários para a melhoria da educação, só podem ser compreendidos, quanto aos seus propósitos reais, a partir da sua raiz teórica e da forma como se materializa na escola.

Deste modo, pode-se afirmar que a característica gerencial, pragmática, pontual e estratégica do PDE dificilmente se constituirá em base para a construção de um projeto pedagógico único, consistente, articulado e emancipador na relação entre sujeito e conhecimento. Esse instrumento não tem uma fundamentação teórica capaz de fazer a mediação entre a gestão e o processo de ensino e aprendizagem. Essa desarticulação dá provas de que o ensino de qualidade não se sustenta sobre projetos que insistem em manter a fragmentação e desarticulação do conhecimento, bem como a priorização do aspecto técnico em detrimento do político.

Apesar do caráter inovador atribuído ao PDE, nas suas raízes encontram-se teorias administrativas que são sustentáculos históricos da organização escolar. Essas teorias assumem somente uma nova roupagem que resulta na realimentação de velhas práticas e na introdução, apenas, das reformas necessárias.

Nesse sentido, Gurgel (2003, p. 25) sustenta a tese de que

a teoria e a tecnologia de gestão e produção contemporâneas, aparentemente fragmentadas e contraditórias, têm predominâncias e elementos comuns que permitem reuni-las em corpo teórico consentâneo com a forma atual do desenvolvimento capitalista.

Assim, para o autor, os valores e as crenças tanto das primeiras teorias de gestão quanto das contemporâneas, os seus métodos e as 
suas técnicas, independente do tempo e da forma, constituem-se em forças objetivas na afirmação e reprodução das relações sociais. Portanto, para além de seu caráter técnico de organização do trabalho, cumpre, fundamentalmente, uma função ideológica no sentido de veicular valores universais que são historicamente necessários para o desenvolvimento e a sustentação do capitalismo.

Para realização dessa tarefa, as teorias administrativas são generalizadas e estendidas para os diferentes e diversos tipos de organização. Nesse caso, a escola, entendida como uma organização que, historicamente, não logrou construir um corpo teórico próprio de administração (FéLIX, 1985), tem incorporado na sua prática administrativa, entre outras razões históricas, tais teorias.

Entretanto, há possibilidade da administração e da gestão escolar assumirem outro caráter, o que vai depender da intenção ideológica e das concepções que animem um projeto societário.

\begin{abstract}
The School Development Plan (PDE) is a product of the Fundescola program, aimed at perfecting the management of public schools with a view to improving the quality of teaching. The Program hopes that through this product, schools will incorporate strategic planning and the principles of total quality as a method. This article presents an analysis of the theoretical fundamentals on which the PDE is based, starting from a study of its methodology and the respective processes of drawing it up and implementing it in a public school in the municipality of Dourados-MS, in the period between 1999 and 2002. The study helped to visualize how an ideology implicit in contemporary educational policies is presented in the day-to-day running of a public school.
\end{abstract}

Key words: Educational policy; school management; public schools; primary education.

\title{
NOTAS
}

1. Intitulada "Plano de Desenvolvimento da Escola - PDE: a gestão escolar necessária frente às diretrizes educacionais do Banco Mundial", sob a orientação da profa. dra. Maria Dilnéia Espíndola Fernandes, no ano de 2005.

2. O estado de Mato Grosso do Sul (MS), localizado na região Centro-Oeste, foi contemplado com as ações do programa Fundescola em 1998. Para iniciar 
efetivamente suas ações no estado, priorizou-se a microrregião da capital e cidades do entorno, compondo a ZAP-1. Em 1999, o programa foi expandido para a segunda microrregião do estado, denominada ZAP-2, tendo como cidade-pólo o município de Dourados. Neste município, o PDE foi introduzido em seis escolas estaduais e sete municipais. Até o final de 2002, o PDE estava sendo implementado em vinte e cinco escolas municipais e quinze estaduais.

3. A rede municipal de ensino de Dourados contava, no período 1999-2002, com 34 escolas, sendo 25 localizadas na área urbana, três na urbana distrital e seis na área rural. Estas escolas atendiam, em 2002, um total de 18.146 alunos do ensino fundamental.

4. O contato profissional desta autora com o objeto em foco também colaborou para a análise. A pesquisadora atuou como membro do grupo de desenvolvimento da escola (GDE) - função ligada à estrutura gerencial do PDE/Fundescola - no âmbito da Secretaria Municipal de Educação de Dourados, sendo responsável em acompanhar a elaboração e implementação do PDE nas escolas, no período de 1999 a 2003.

5. O entendimento de qualidade de ensino é delineado por diversas e diferentes concepções. Resumidamente, são oriundas: dos conceitos ligados a empresas privadas, que se preocupam com a produtividade; das orientações dos organismos credores, que se preocupam com a relação de custo-benefício; de governos de oposição, que se preocupam com os direitos sociais de cidadania.

\section{REFERÊNCIAS}

AMARAL SOBRINHO, J. O plano de desenvolvimento da escola e a gestão escolar no Brasil: situação atual e perspectivas. Brasília: Fundescola/MEC, 2001. (Série Documentos, n. 2).

Reflexões sobre a escola. In: nos "is". [S.I.: s.n.], [s.d.]. Mimeografado. Gestão escolar: colocando pingos

BRASIL. Fundo de Fortalecimento da Escola. Projeto de Melhoria da Escola: manual de orientação. 2. ed. Brasília: Fundescola, 1999.

Ministério da Educação. Fundo de Fortalecimento da Escola. Como elaborar o Plano de Desenvolvimento da Escola. Caderno de transparência. Brasília, 2002.

CAMINI, L. (Coord.) et. al. Educação pública de qualidade social: conquistas e desafios. Petrópolis: Vozes, 2001.

CHIAVENATO, I. Introdução à teoria geral da administração. 5. ed. São Paulo: Makron Books, 1997. 
ETZIONI, A. Organizações modernas. 7. ed. São Paulo: Pioneira, 1984.

FÉLIX, M. de F. C. Administração escolar: um problema educativo ou empresarial? São Paulo: Cortez: Autores Associados, 1985.

GURGEL, C. A gerência do pensamento: gestão contemporânea e consciência neoliberal. São Paulo: Cortez, 2003.

MARRA, F.; BOF, A.; AMARAL SOBRINHO, J. Plano de desenvolvimento da escola: conceito, estrutura e prática. Fundescola-MEC/Bird, 1999.

MOTTA, F. C. P. Teoria geral da administração: uma introdução. 22. ed. amp. São Paulo: Pioneira, 1998.

OLIVEIRA, D. A. Qualidade total na educação: os critérios da economia privada na gestão da escola pública. In: BRUNO, L. (Org.) Educação e trabalho no capitalismo contemporâneo: outras leituras selecionadas. São Paulo: Atlas, 1996. p. 57-90.

OLIVEIRA, J. F. de; FONSECA, M.; TOSCHI, M. S. Educação, gestão e organização escolar: concepções e tendências atuais. In: FONSECA, M.; TOSCHI, M. S.; OLIVEIRA, J. F. de (Orgs.). Escolas gerenciadas: planos de desenvolvimento e projetos político-pedagógicos em debate. Goiânia: Ed. da UCG, 2004.p. 21-33.

OLIVEIRA, M. A. M. Controle da qualidade total: uma gestão salvadora? In: . Escola ou empresa? Petrópolis, RJ: Vozes, 1998. p. 41-96.

SANDER, B. Gestão da educação na América Latina: construção e reconstrução do conhecimento. Campinas: Autores Associados, 1995.

XAVIER, A. C. da R.; AMARAL SOBRINHO, J. Como elaborar o Plano de Desenvolvimento da Escola: aumentado o desempenho da escola por meio do planejamento eficaz. 2. ed. Brasília: Programa Fundescola, 1999. 